\title{
Special Issue on the High-Temperature Corrosion in Mixed Oxidant Environments
}

\author{
Michel Vilasi ${ }^{1} \cdot$ B. Pint ${ }^{2} \cdot$ D. Monceau $^{3}$
}

Received: 11 February 2017/Published online: 23 February 2017

(C) Springer Science+Business Media New York 2017

There is a large variety of technological processes that operate at high temperatures and where equipment service life is strongly influenced by high-temperature oxidation and corrosion processes. Most examples are found in the fields of the energy production and conversion, notably in fossil energy conversion plants, in nuclear power plants, in jet engines and in processes of the chemical and petrochemical industries.

There has been much effort over the years directed at elucidating corrosion mechanisms, which can be numerous and diverse because of the variability of the complex aggressive environments encountered. Indeed, the atmospheres originated by many advanced industrial processes are very rarely single oxidant, as illustrated by most of combustion gases which invariably contain carbonaceous species, water vapor and quite commonly sulfur and vanadium species derived from the impurities present in most fossil fuels.

In addition, liquid phases are apt to be formed and deposited on the surface of components as a result of interactions between the combustion gases and inorganic

Michel Vilasi: Topic Editor; B. Pint, D. Monceau: Guest Editors

Michel Vilasi

michel.vilasi@univ-lorraine.fr

B. Pint

pintba@ornl.gov

D. Monceau

daniel.monceau@ensiacet.fr

$1 \quad$ IJL-UMR 7198 CNRS, Université de Lorraine, Bd des Aiguilletes, BP 70239 ,

54506 Vandoeuvre les Nancy Cedex, France

2 Materials Science and Technology Division, Oak Ridge National Laboratory, Oak Ridge, TN 37831-6156, USA

3 INP Toulouse-CNRS CIRIMAT, 31030 Toulouse, France 
compounds present in the atmosphere such as halide, sulfate, carbonate or aluminosilicate salts. In such cases, aggravated degradation of materials is expected due to the superpositioning of chemical degradation processes, e.g., oxidation and oxide dissolution by fluxing or by gaseous halogenide formation ("active oxidation").

The papers in this special issue deal with various corrosion mechanisms that highlight, on the one hand, the chemical effect of a various corrosive environments (molten sulfate-vanadate-chloride and also liquid sodium) and, on the other hand, the behavior of conventional nickel-based superalloys, stainless and carbon steels, but also of titanium alloys, intermetallic silicides and ceramics. There is also an outstanding overview paper on "future directions in the field of high temperature corrosion research."

The papers stem from presentations at the 9th International Symposium on High Temperature Corrosion and Protection of Materials (HTCPM2016), which was held at Les Embiez, France, on May 15-20, 2016. 